\title{
Managing of Renewable Energy Transformations in Egypt
}

\author{
Mohamad F . Fayad ${ }^{1}$, Sherif Sabri ${ }^{2}$, Maged Elmahdy ${ }^{3}$, A. Alrahim Kasem ${ }^{3}$ \\ 1 Doctoral Researcher, Urban planning Department, Engineering Faculty of Al-Azhar University, Cairo, Egypt. \\ 2 Professor Emeritus, Urban planning Department, Engineering Faculty of Al-Azhar University, Cairo, Egypt. \\ 3 Professor, Urban planning Department, Engineering Faculty of Al-Azhar University, Cairo, Egypt. \\ Corresponding author: engmohamad.farag@gmail.com
}

\begin{abstract}
There is an urgent need to shift from energy systems based on fossil fuels to systems based on renewable resources to reduce dependence on depleted reserves of fossil fuels with the aim of assessing whether Egypt is able to sustain its growth and its society with regeneration. Resources. This paper discusses the shift towards renewable energy in making sustainable development strategies. These strategies typically involve three major technological changes: saving energy on the demand side, improving efficiency in energy production, and replacing fossil fuels with various sources of renewable energy. Thus, large-scale renewable energy implementation plans should include strategies on how to integrate renewable resources into coherent energy systems affected by energy provision and efficiency measures. Depending on the case of Egypt, this paper discusses the diverse energy opportunities, problems, and perspectives of converting existing energy systems into a renewable energy system; It will also focus on analyzing the main challenges facing the renewable energy strategy in Egypt. Therefore, the application of the new and renewable energy sources available in Egypt is now a major issue in the future strategic energy planning of fossil traditional energy alternatives to provide part of the domestic energy demand. New governance models are needed to visualize and direct the energy transition in a more sustainable direction. Therefore, this paper used the Transition Management Governance Framework to answer the question: In order to achieve and manage the energy transition towards renewable sources, The analysis of the proposed model relied on three levels: strategic (structuring and visualizing the problem), tactical (building a coalition, developing a transitional agenda), and an operational level (mobilizing actors and carrying out experiments). The conclusion is that such a transformation will be possible; Necessary renewable energy sources are in place, if further technological improvements of the energy system are to be achieved, especially transmission conversion technologies and the introduction of resilient energy system technologies is critical.
\end{abstract}

Keywords: Renewable Energy, governance, transformation, sustainable city, Sustainability. 


\section{Introduction}

Many cities recognize this and have adopted ambitious sustainability targets and agendas. City officials implementing these are often confronted with the limitations of available policy instruments, which leave them little leeway in dealing with the complexity of sustainability issues. Far from clear-cut, these can best be regarded as persistent problems: deeply embedded in society, involving a myriad of interrelated actors, domains, and scales, with no obvious starting point.

To address them, we need fundamental shifts in structures, mind-sets, and practices- in other words, sustainability transitions. [1]

Fortunately, local governments do not stand alone in their desire to realize structural change toward sustainability. Many citizens, companies, and non-governmental organizations (NGOs) have set up initiatives to contribute to a sustainable future. Even if they do not explicitly aim to contribute to a sustainable future, still they make decisions that influence this future every day. How can city officials be working towards a sustainable future tap into this potential? How can they get a feeling for the dynamics of societal change in their city? How might they identify, access, and engage with these dynamics to strengthen, connect or streamline emerging sustainability initiatives, or create conditions for the emergence of others?

To assist city officials who struggle with these questions and seek ways to foster a sustainable future for their city, the Dutch Research Institute for Transitions (DRIFT, Erasmus University Rotterdam) has developed the Transition governance approach, which is based on insights from complex systems, governance and sociological theories.

\section{Transition and transition governance}

\section{Transition theory}

A transition is the move from a relative stable framework (dynamic harmony). Although a time of generally fast change during which the framework rearranges irreversibly into another (steady) framework again [2]. Changes have the accompanying attributes [3]:

1. They concern huge scope innovative, practical, biological, socio-social, and institutional improvements that impact and strengthen one another.

2. They are long haul forms that take at any rate one age.

3. There are connections between various scale levels (specialty, system, and scene).

Rotmans stated that when we reach to the point that we understand transitions in societal systems then it would be possible to steer this process by a Transition governance. In general, it is possible to characterize all transitions into four phases [4]. The four phases can be seen in figure 1 , where they are characterized by a S-shaped curve. The different phases are called predevelopment, take-off, breakthrough, and stabilization phase. These phases can be understood as follows:

The first phase describes small changes in a system, where actions are mainly taking place on an individual level. The take-off phase already sees a higher level of interaction between actors and considers that a change has already started in the system. This could mean that some businesses already established successfully transition practices and the topic became 
more and more on the agenda of politicians. People started to see it as an important topic and doubt whether the current system of how we handle our resources and goods is the right one. A visible change of the system is described as breakthrough phase. Legislations have already been set that require a development towards transition and demand a similar development of businesses. A system change is inevitable at this point. The stabilization phase is characterized by a decrease of disorder and the establishment of the new system [5]. A more detailed description and explanation of these four phases will be undertaken in the next sections.
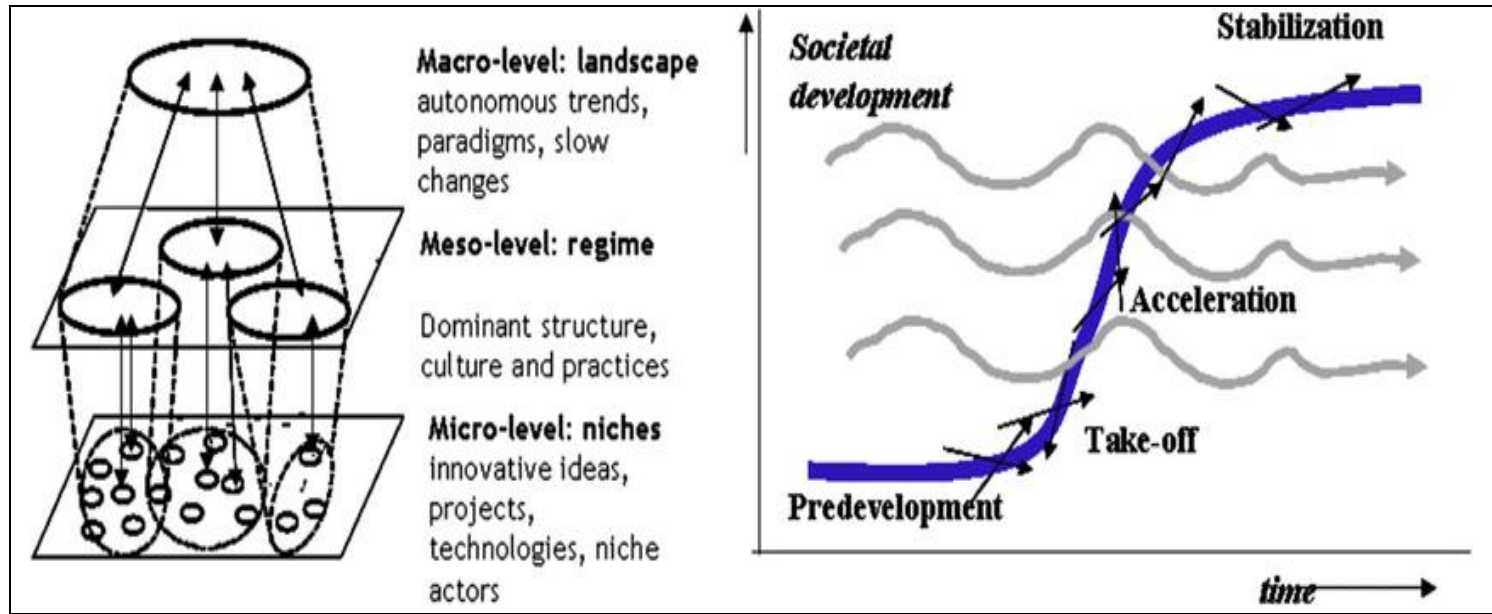

Figure 1. Multi-level and multi-phase models of transitions.[6]

\section{Transition governance}

Transition governance is based on the empirical and theoretical insights of transition studies and offers ways to influence the direction and pace of societal change dynamics towards sustainability [7].

The approach has been used to stimulate sustainability transitions in localities (e.g. regions, cities, and neighborhoods), and to initiate transformations in socio-technical systems, such as energy, water, and mobility. The Transition governance approach proposes six principles for influencing transitions:

1) Insight into the system: The complexity of the challenges must be fully acknowledged.

2) System innovation in incremental steps: The aim is to go beyond system improvements and optimization to system innovation.

3) Diversity and flexibility: The future can neither be predicted nor planned, so it is essential to keep options open by exploring multiple pathways when working on strategies and actions.

4) Co-creation. Neither local government nor any other single actor can address sustainability challenges on its own.

5) Creating opportunities for change agents. Achieving ambitious targets is difficult when vested interests and positions are taken as a starting point.

6) Facilitate social and institutional learning: Learning is essential for societal change.

These governance principles have been translated into a governance framework, the transition management cycle, which distinguishes between four scopes of activities: strategic, tactical, operational (see fig.2). [8]. 


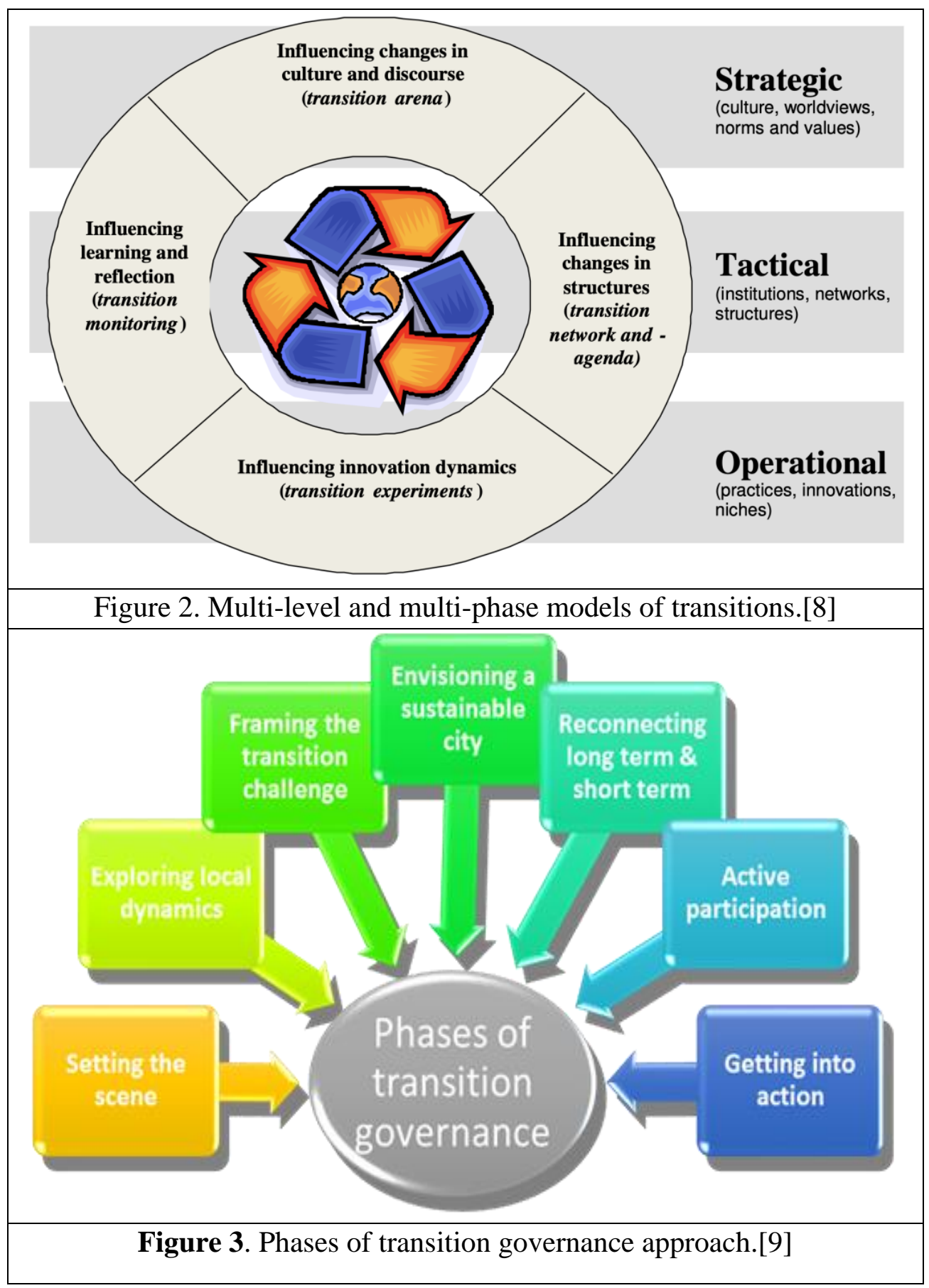

The process structure and methods in this chapter provide guidance for implementing the Transition governance approach. It is not a universally applicable blueprint; it provides a structure, which needs to be adapted to the specific circumstances of and dynamics emerging throughout the process.

The table below (table 1) broadly outlines the process structure, distinguishing between seven (partly overlapping) phases that can guide the implementation of the process [10] 
Table 3. The seven phases of transition governance approach [10]

\begin{tabular}{|c|c|}
\hline Phases & Implementation \\
\hline $\begin{array}{l}\text { 1-Setting the scene } \\
\text { for transition } \\
\text { governance }\end{array}$ & $\begin{array}{l}\text { A transition team is formed to drive the process and embed it in } \\
\text { the local context. }\end{array}$ \\
\hline $\begin{array}{l}\text { 2-Exploring local } \\
\text { dynamics }\end{array}$ & $\begin{array}{l}\text { The transition team starts to explore the city's dynamics, } \\
\text { conducting interviews and doing desk research, and working } \\
\text { towards a system analysis and actor analysis. Based on the actor } \\
\text { analysis, a diverse group of change agents is invited to engage in } \\
\text { a series of meetings as a transition arena group. }\end{array}$ \\
\hline $\begin{array}{l}\text { 3-Framing the } \\
\text { transition challenge }\end{array}$ & $\begin{array}{l}\text { The change agents first explore the transition challenges and } \\
\text { create a shared problem framing. }\end{array}$ \\
\hline $\begin{array}{l}\text { 4-Envisioning a } \\
\text { sustainable city }\end{array}$ & $\begin{array}{l}\text { Subsequently, they exchange and elaborate perspectives on a } \\
\text { possible future, thereby creating visionary images for the future } \\
\text { of the city. }\end{array}$ \\
\hline $\begin{array}{l}\text { 5-Reconnecting long } \\
\text { term \& short term }\end{array}$ & $\begin{array}{l}\text { As a final step in the transition arena setting, the change agents } \\
\text { elaborate transition pathways, indicating fundamental changes } \\
\text { and corresponding actions needed to reach the envisioned future. } \\
\text { The ideas brought forward by the transition arena are } \\
\text { summarized and published in a transition agenda. }\end{array}$ \\
\hline $\begin{array}{l}\text { 6-Active } \\
\text { participation }\end{array}$ & $\begin{array}{l}\text { Actions are undertaken to make the transition agenda public and } \\
\text { give others a chance to adopt and adapt it, and relate it to their } \\
\text { own agenda and practices. }\end{array}$ \\
\hline 7-Getting into action & $\begin{array}{l}\text { Transition experiments, radical short-term actions in line with } \\
\text { the transition agenda, are initiated or adapted. Through these } \\
\text { actions, more actors become engaged. Insights from these } \\
\text { experiments can be taken to a more strategic level }\end{array}$ \\
\hline
\end{tabular}

The suggested sequence of phases helps to get a grip on the process, but it is not set in stone. For example, a city could also start fostering transition experiments to widen the range of alternative practices, and subsequently derive visionary images and transition pathways by reflecting on the larger meaning of these experiments.

\section{3- Transition to renewable energy systems}

In order to tackle climate change, we need to be asking questions of practicality: how can we transition the world's energy infrastructure away from gas and coal, while also meeting dramatically increased overall global demand? 
To make the switch - what will it take for businesses, governments and industries to transition to renewable energy?

The path for policymakers trying to remove polluting fuels from our energy system has never run in a straight line. Over 20 years after the current series of United Nations climate change conferences began, the share of global energy consumption provided by fossil fuels remains over $80 \%$, according to International Energy Agency figures. Global energy consumption has increased by over $45 \%$ in the past 20 years and production of coal and natural gas has risen even faster. [11]

At the latest climate change conference in Katowice last year, governments with heavy economic reliance on both coal and gas, including the United States, refused to endorse scientific advice on climate change. But we should not see the energy transition problem as a binary opposition between fossil fuel producers and renewable energy leaders.

While it's true that the Trump administration has championed the coal industry, the fact is that coal is already on its way out in the US, and more so than in some other countries. To understand the challenge facing advocates of energy transition, we need to distinguish between the transition from coal and the transition from gas. [12]

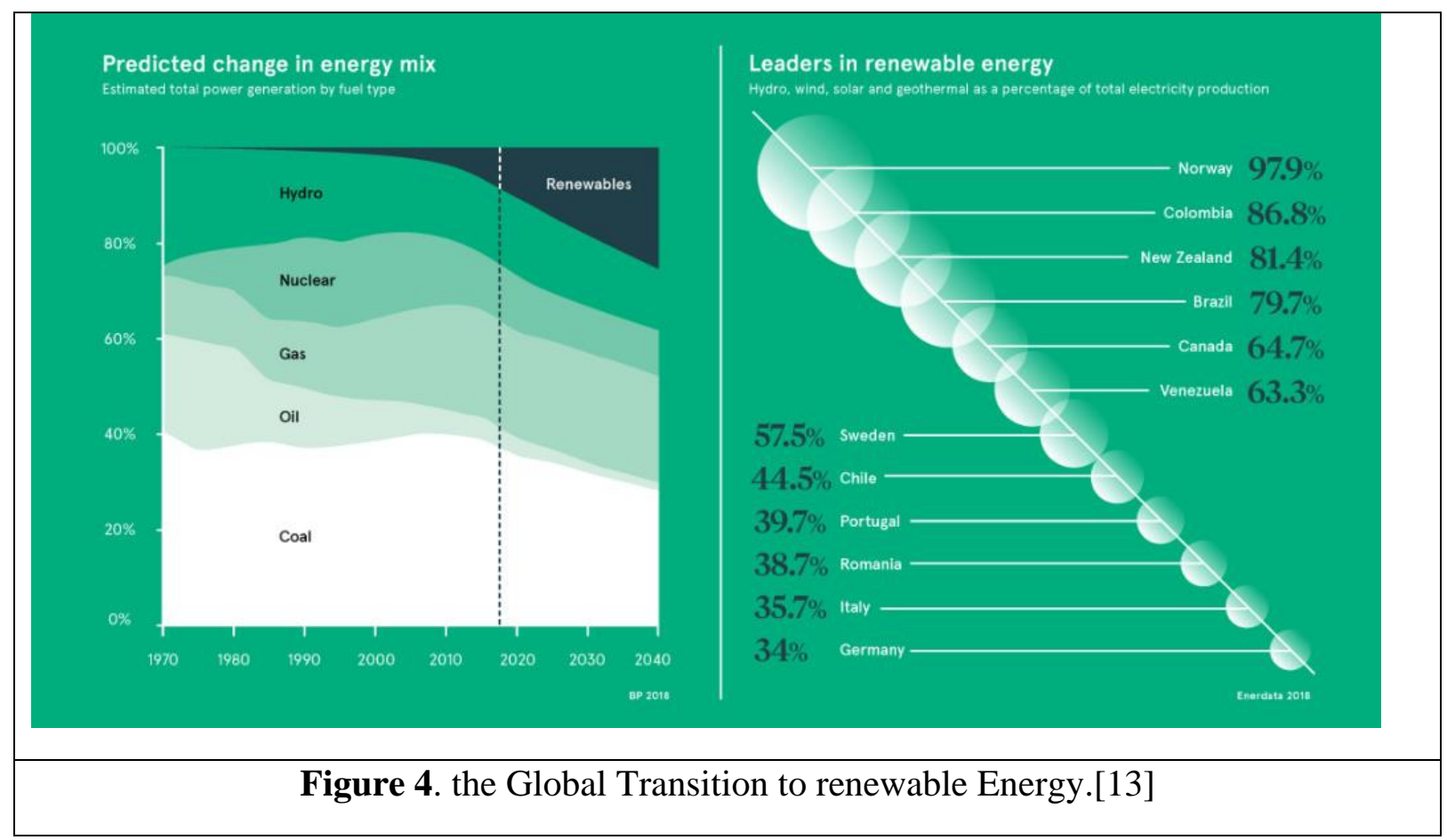

In North America today, there are no plans to build new coal-fired power stations and the economics for coal get worse with every passing year. In those parts of the US that operate competitive power markets, coal-fired power struggles to compete with natural gas on price. Moreover, the kind of large-scale, constant baseload power which coal-fired generation excels at providing is becoming less important. Over the past 40 years, the US and other developed economies have de-industrialised. Energy-hungry heavy industries have given way 
to service industries with much lighter electricity demand. As a result, overall electricity consumption in the world's largest economy is falling. The spread of data centres will not be enough to offset this trend, and neither will electric vehicles (especially with the relatively sluggish take-up of the latter in the US). Changes in working patterns mean that demand on the power grid is not as predictable as it used to be. [14]

Smart meters mean that consumers can see in real time how much power they are consuming and adjust their consumption accordingly. The huge growth in renewables, meanwhile, has transformed the energy supply proposition in North America. Wind and solar power have no variable cost of production: the wind and sun are free, so whenever they appear, electricity gets generated. This acts like negative demand on the grid, further reducing the demand for baseload power.

In emerging markets, on the other hand, coal is the cheapest fuel available. For countries like India, China and the states of South-East Asia, with growing economies and increasing demand for power, domestic coal production remains an attractive way to sustain economic growth at a price point that most of the population can still afford. Over $300 \mathrm{GW}$ of new coalfired power generation - more than the output of all the coal-fired power stations in the US and Canada combined - was being planned or constructed as late as last year, most of it in these countries. [15]

Transitioning away from coal, therefore, requires different measures in different parts of the world. In the US, still the third-largest user of coal-fired power by capacity, market forces will lead to much of the current fleet being decommissioned in the coming years. However, this only applies in competitive markets where power production is separated from energy supply. If power markets across the country were open to competition, this could be accelerated - although political support for the coal industry (which includes coal mining and haulage as well as power) is likely to prevent that for the foreseeable future.

Market forces can also work outside the US, where in some countries - particularly in Latin America - the fall in the cost of renewables means they can compete with fossil fuel generation. Where coal remains competitive on price, natural gas can be a bridging fuel to renewables, replacing coal as the main provider of baseload capacity. Gas-fired peaking plants, which are designed to be started up quickly in response to urgent demand for electricity in peak periods, are considerably cleaner than coal plants and quicker to start up. The shale gas boom in North America has made natural gas more competitive. Asian countries with insufficient domestic gas production have already invested in infrastructure to import liquefied natural gas and further investment could reduce their reliance on burning coal. The transition from gas will be harder, not least in the US, which now produces so much gas that it became a net exporter for the first time in 2017 and is due to scrap tax credits for renewable energy generation in the coming years. As solar cell technology improves and wind turbines become more powerful, renewables are becoming more cost competitive on a price per kilowatt-hour basis, but this alone is not enough. To compete overall, they must also be as reliable as fossil fuels, and that means when combined with batteries or other technology able to supply power when wind and solar are not generating. At their current 
price, the cost of large-scale batteries needs to fall by about $50 \%$ before this can occur. [16]

A cost-effective solution already exists, however, in the form of capacity markets. Such markets sell power capacity to energy suppliers to guard against power outages at peak times. This can be in the form of either increased generation or of reduced consumption, such as a factory that offers to switch off its machinery temporarily at peak times when demand is high. Smart grid technology can help to aggregate capacity providers, as well as to schedule power demand - such as for charging electric vehicles - away from peak times. If capacity markets are combined with markets for carbon credits, this could cancel out some of cheap gas' competitive advantage. In the longer term, the most important technological advance in the energy transition will be in battery storage.

Both government and energy infrastructure professions have a part to play here. Governments who have committed to phasing out fossil fuels can put their money where their mouth is by investing in research and creating incentives to spur innovation in the field of energy storage. The energy infrastructure professions meanwhile face a re-skilling challenge, with a generation of experts in coal-fired power finding increasingly little to do in countries that have turned their backs on coal.

There is already no shortage, at least in the US, of people eager to take jobs in the renewable energy industry. But like other industries, this sector will be increasingly driven by automation at all levels, from project origination through design to asset management. Energy efficiency and balancing increasingly variable supply with price-sensitive demand relies on ever-increasing flows of data.

Both industry veterans and new entrants will have to get to grips with the power of automation and making sense of data streams; either by up-skilling or by partnering with service providers. At the same time, the spread of capacity markets could bring new entrants to the energy industry in the form of heavy-duty industrial consumers. Professionals at these firms who can master energy efficiency, data analytics and power trading are well placed to capitalize on the energy transition. 


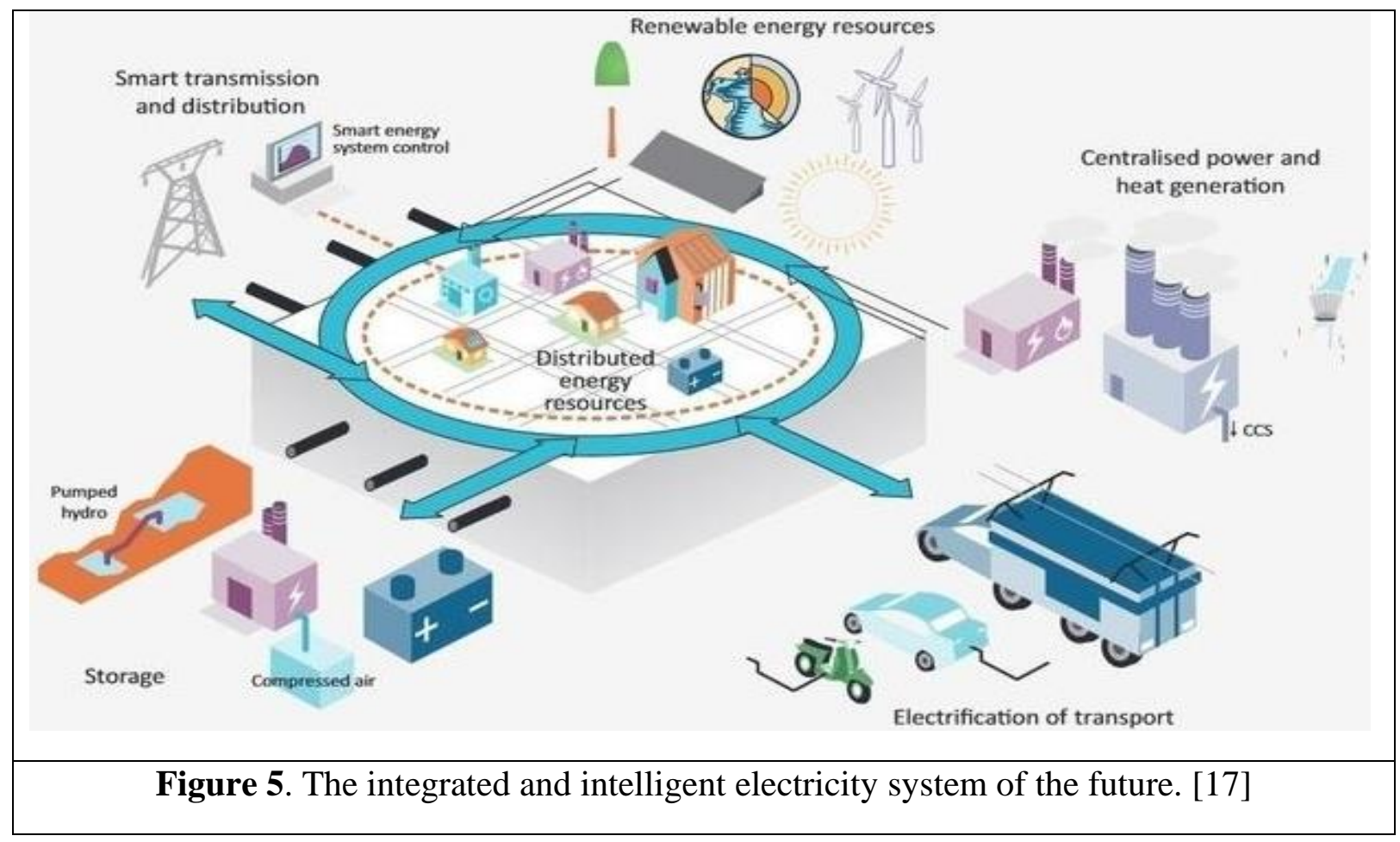

We need to transform our energy systems. Why does this present such a challenge? We already see many solar panels on rooftops, and horizons are sometimes filled with windmills. The prices of these technologies are decreasing, making them available for more and more people. In some cases, they are already competing economically with fossil fuel based systems. Is it then not just a matter of time? If we wait long enough, will renewables eventually take over our energy mix because of availability and price? Several changes in energy systems are beginning to work their way. To mention only a few:

- Large-scale adoption of affordable PV-systems in several countries

- Rapid development of wind technology; development of large-scale wind farms

- Electrification of transport

- Network developments

- grid modifications to facilitate decentralized energy systems.

- transforming distribution networks to smart grids to allow intelligent matching of local demand and supply.

- expanding and interconnecting transmission networks to connect large-scale wind farms and solar parks in favorable locations to centers of demand.

- Inclusion of large-scale energy storage -- pumped-hydro systems and compressed air storage systems.

\section{4- Renewable energy transition in Egypt}

The renewable energy sector in emerging markets is sparking interest from investors, financiers and operators alike. Egypt is among the countries undergoing significant transformations in this field, by seeking to address the energy crisis it has been facing for 
years by changing its electric energy mix to include 20 percent of renewable energy sources by 2022 .

While the Egyptian government expects that 12 to 14 percent of clean energy will be generated by relying on wind energy, the focus is currently on the Benban project, which, upon completion, will become the largest solar photovoltaic project on earth. [18]

With a population of 100 million people, Egypt tops the list of Arab countries in terms of population and comes third in Africa after Nigeria and Ethiopia. The steady increase in the number of citizens has led to a rapid growth in energy demand, which has caused a fuel crisis that has escalated since 2014, despite the major marine natural gas discoveries that the country has recently known.

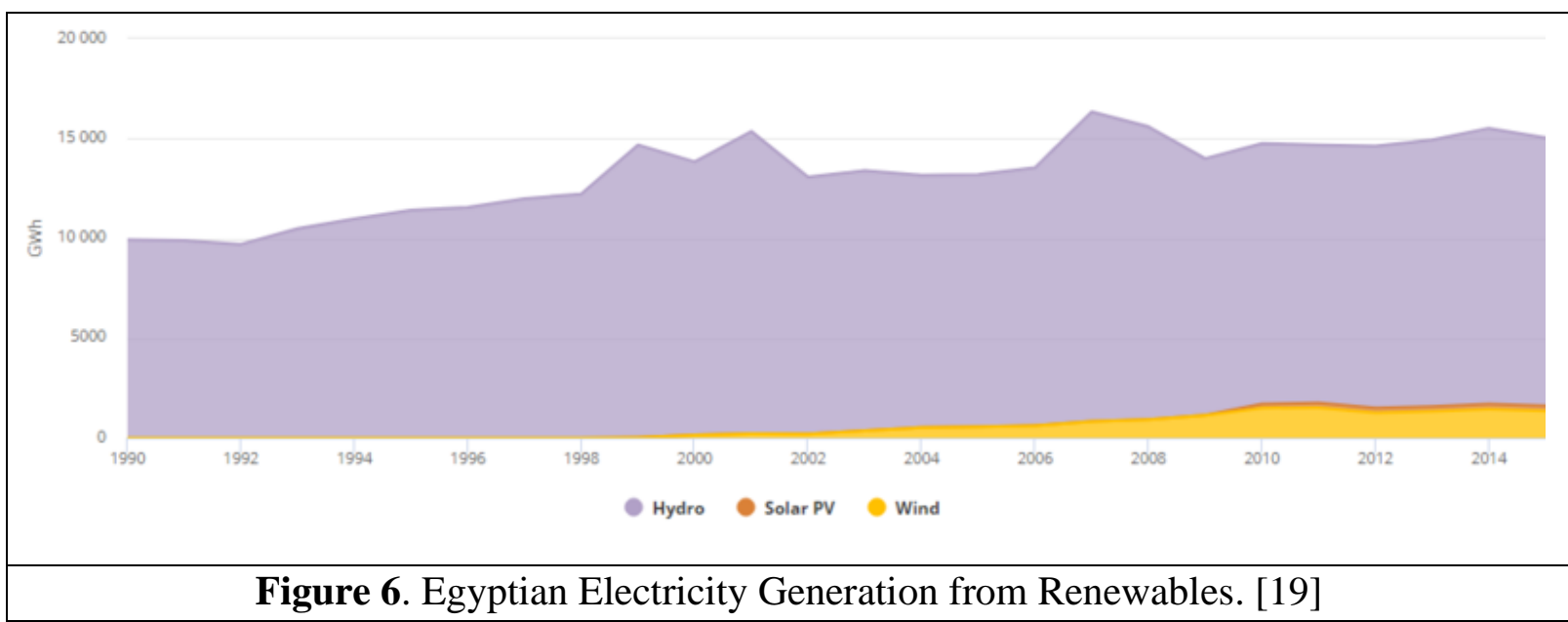

With the abundance of its lands, and its enjoyment of sunny weather and high-speed winds, Egypt realizes the importance of its renewable nature wealth that can help meet the increasing demand for energy and move to a more sustainable and environmentally diverse electricity sector. The "Integrated and Sustainable Energy Strategy to 2035", adopted by the Egyptian government in 2016, stresses the importance of renewable energy in its endeavor to ensure the security and stability of the country's energy supplies. [20]

According to the "Renewable Energy Outlook in Egypt" report, issued in 2018 by the International Renewable Energy Agency, in cooperation with the Egyptian Ministry of Electricity, the total installed capacity of renewable energy sources in the country is 3.7 gigawatts, including 2.8 gigawatts of hydropower, and about 0.9 gigawatts of solar energy. And wind power. These capacities are relatively modest when compared to the total installed electricity capacity in 2018, which reached 50 gigawatts. [20]

According to what is specified in the integrated and sustainable energy strategy, the Egyptian government has set goals to increase the contribution of renewable energy to reach 20 percent of the electric energy mix by 2022, and 42 percent by 2035 . 


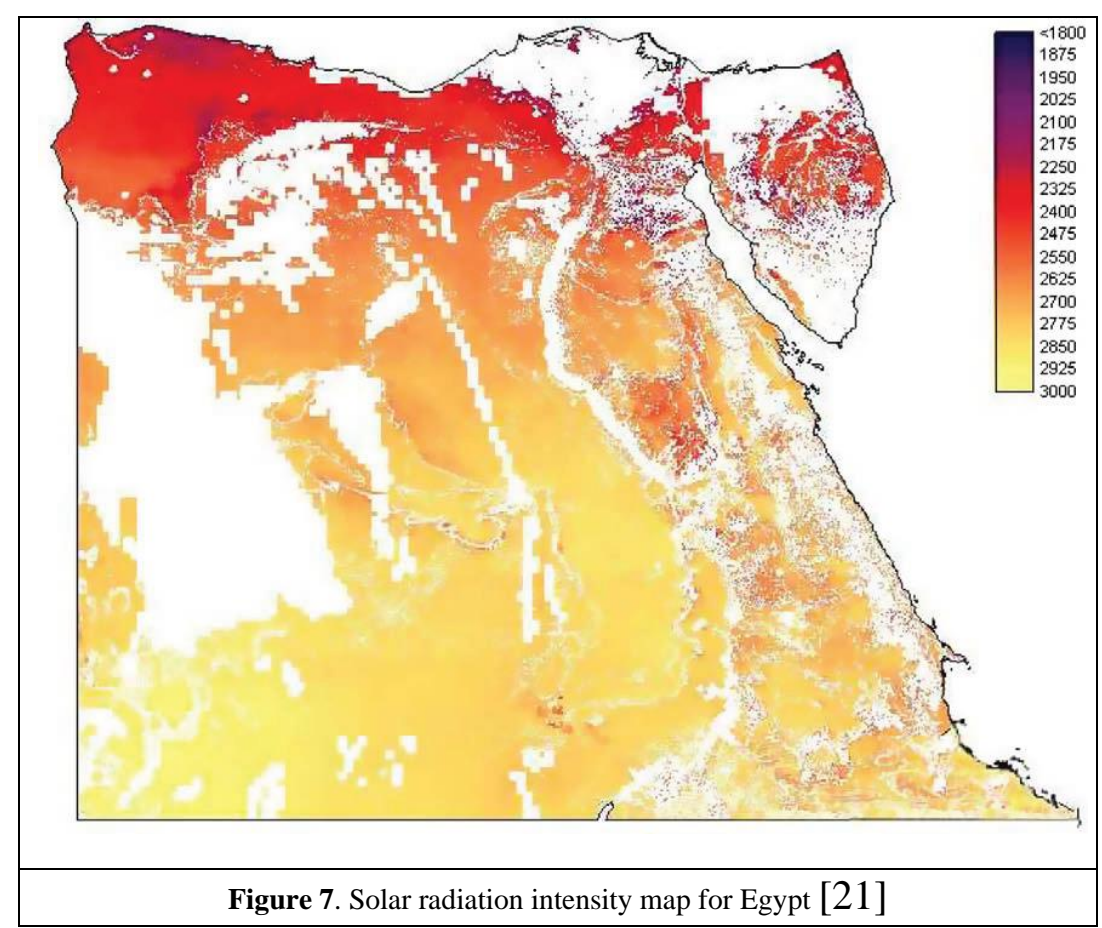

In contrast, the analysis of the "Renewable Energy Road Map" developed by the International Renewable Energy Agency concludes that Egypt is able to provide 53 percent of the electric energy mix by relying on renewable sources by 2030 .

While the energy sector accounts for about 13 percent of GDP, the agency's analysis indicates that the increased spread of renewable energy technologies will lead to a reduction in total energy costs by $\$ 900$ million in 2030, which means a decrease in the cost by $\$ 7$ per megawatt hour, regardless. On the decrease in the total costs related to air pollution, and its social and health impacts, which are estimated to reach 4.7 billion dollars in 2030 .

Egypt's sustainable development goals in the field of energy are to achieve ensuring security of supplies to meet the country's future needs, through adopting a diversified energy mix, direct investment, rationalizing consumption, and reforming energy subsidies. The goals also include ensuring the technical and financial sustainability of the energy sector, improving institutional management, and strengthening markets and competitive regulations.

Egypt's renewable energy projects are at the forefront of the solar power plant in Benban in Aswan, which will generate 1,600 megawatts with photovoltaic technology, and the wind power plant in Jabal al-Zayt in the Red Sea, with a total capacity of 580 megawatts, in addition to the Dabaa nuclear power plant in Matrouh, capable of Its amount is $4800 \mathrm{MW}$. But the plan also includes a huge plant in Hamraouine, on the Red Sea coast, to produce electricity from coal, with a capacity of 6 thousand megawatts, under the name of "clean coal."[22]

Professor of Energy and Environment at the Arab Gulf University, Dr. Ibrahim Abdel-Jalil, believes that "one of the most important reasons for Egypt to start implementing solar energy 
projects, and renewable energies in general, is that it completes the legislative and institutional framework necessary to implement these projects, which is necessary to attract investments in this promising sector of the national economy. Although Egypt enjoys huge resources of solar energy, and with many attempts since the early eighties of the last century, the expansion of the exploitation of these resources did not witness a real breakthrough until after the completion of that framework. But he puts a question mark over the concept of "clean coal".

Egypt had adopted its first renewable energy strategy in 1982, targeting the production of 5 percent of the electricity generated from renewable sources by the year 2000, but this goal was not achieved, due to the relatively high cost of renewable energy technologies, and the prices of heavily subsidized energy during that period. . In 2008, a target of 20 percent renewable energy was set by 2022, but political instability, combined with economic uncertainty, meant that strategic goals for renewable energy remain suspended without implementation.

Then the country began to devote renewable energy in its legislation and plans, starting with the 2014 constitution, which approved obtaining the maximum benefits from renewable energy sources, stimulating investment in them, and encouraging research and development, in addition to local manufacturing. This was followed by a decision in 2015 to allocate lands for renewable energy projects, and the new electricity law in the same year, which provided the legislative and regulatory frameworks necessary to achieve the goals of reforming the electricity market, leading to the investment law in 2017 that guarantees investment guarantees.

\section{A paradigm for managing renewable energy transition in Egypt.}

The proposed paradigm depends on these steps:

\section{Strategic level: problem structuring and envisioning.}

The purpose of the strategic level of TM is to establish a vision to mobilize potential and encourage actors to commit to an overarching goal that guides the transition. How- ever, before formulating the vision, it is essential to agree on a new shared approach on how problems at the system level should be tackled. For the energy system, it means identifying and understanding the selection pressures that are disturbing the current system and demanding change. This section will begin by briefly discussing the key features of the Palestinian energy system, highlight the selection pressures, then present the new energy transition vision, While more than $90 \%$ of the Egyptian generated electricity comes only from oil and natural gas, the major problem that Egypt encounters, especially in the energysector is the dynamic growth of population, which is estimated by around $1.3 \%$ per year, consequently increasing demand, which eventually fastens the rate of depleting the country's major resources [20]

\section{Tactical level: coalition building and developing transition agendas.}

After creating a new discourse and establishing a vision, a transition agenda should be created, which is the objective of the tactical level. This entails translating the vision into 
specific goals, and strategies whilst simultaneously building networks to innovate, manage, and sustain the process Transition images and paths are used as instruments to pro- duce the agenda, which are defined as the collective images that formulate the overall vision, and the required routes to reach those images through intermediate milestones [23]. This section will briefly present the main transition paths and coalition building efforts. According to the Ministry of Electricity and Renewable Energy (MoERE), 54 GW of new installed capacity (conventional and renewables) is needed by 2022, and on-going reforms in the regulatory framework and subsidies would create large opportunities for the private sector5. In March 2015, the Ministry of ERE highlighted the main challenges as follows:

-Electricity demand growth is exceptionally high (6\% p.a.),

-Power generation deficit (6 GW needed annually by 2022), and

-Energy subsidies had reached 7\% of GDP in 2013/ 2014, but it has been lowered in 2016.

Today, any local authority can adopt incentives for energy efficiency and the development of renewable energy according to the regulations already in place in Egypt according to Law No. 203 of 2014, Law No. 87 of 2015, and Law No. 230 of 2016. Local authorities can also develop information tools to stimulate the local or regional market of energy efficiency and renewable energy development in their city.

\section{$\underline{\text { Operational level: mobilizing actors and implementing transition experiments. }}$}

The focus of the operational level of TM is developing pilot projects (experiments) that use new ideas, insights, and knowledge to make the transition vision and agenda tangible. This level entails nurturing niches of innovation by engaging actors in networking events and concrete pro- jects. The operational level is essential for social learning, coevolution of institutions and technology, and building the necessary confidence to scale-up operations [27]. Renewable energy investments in Egypt are currently widespread and made by diverse actors.

Egypt possesses an abundance of land, sunny weather, and high wind speeds, making it a prime location for renewable energy sources. The renewable energy equipment market is potentially worth billions of dollars. The Government of Egypt is cognizant of the need for a sustainable energy mix to both address increasing demand, and to move to a more environmentally sustainable and diverse electricity sector. The 2035 Integrated Sustainable Energy Strategy, which builds on previous strategies, emphasizes the importance of renewable energy. Egypt intends to increase the supply of electricity generated from renewable sources to $20 \%$ by 2022 and $42 \%$ by 2035 , with wind providing 14 percent, hydro power 2 percent, and solar 25 percent by 2035 . The private sector is expected to deliver most of this capacity. The New \& Renewable Energy Authority (NREA) plays a strategic role in implementing the government's renewable energy plans. It currently has about $500 \mathrm{MW}$ of wind power plants in operation and $1340 \mathrm{MW}$ under development and implementation and is expected to contribute substantially to the rapid expansion of wind power capacity. There are also three privately owned independent power producers (IPPs) with total generation capacity of about 2.5 GW, which started operations 2002-2003 under 20-year long power purchase 
agreements with EEHC. The Egyptian government renewable energy plan for 2015-2023 include $3.2 \mathrm{GW}$ of government projects; including 1.25 GW under BOO mechanisms and $920 \mathrm{MW}$ as IPPs.

\section{Wind Energy}

Egypt enjoys excellent wind along the Gulf of Suez with an average wind speed of 10.5 $\mathrm{m} / \mathrm{sec}$, and Egypt is just one of 38 countries in the world with a published National Wind Atlas. Since 2001, a series of large-scale wind farms have been established, with total capacity of $1.2 \mathrm{GW}$, in cooperation with Germany (KFW), Denmark (DANIDA), Spain (Siemens Gamesa), and Japan (JICA). Implementation of the Spanish project in Jebel El Ziet took place in 2013. In 2014 the implementation of a JICA wind project started with expectations to raise imports by USD 200 million. Another 540 MW project is under construction at Gulf of Suez, a $580 \mathrm{MW}$ project is in financing also at the Gulf of Suez and a feasibility study is under way for a $200 \mathrm{MW}$ project at West Nile. Additionally, more projects are under preparation in cooperation with Germany, AFD, EIB and EU (200 MW), MASDAR (200 MW), Germany and AFD (200 MW), and Japan (200 MW).Recently, the GOE allocated an area of about 7,845 square kilometers in the Gulf of Suez region and the Nile Banks for NREA to implement additional wind energy projects. Launched in 2017, the Ras Ghareb windfarm project, near the Gulf of Suez (approximately $30 \mathrm{~km}$ north-west of Ras Ghareb) is expected to come online in 2019 , produce $262.5 \mathrm{MW}$, and supply power to approximately 500,000 households.

\section{$\underline{\text { Solar Energy }}$}

Egypt's Solar Atlas states that Egypt is considered a "sun belt" country with 2,000 to 3,000 $\mathrm{kWh} / \mathrm{m} 2 /$ year of direct solar radiation. The sun shines 9-11 hours a day from North to South in Egypt, with few cloudy days. The first Solar Thermal Power Plant at Kuraymat was built in 2011. It has a total installed capacity of $140 \mathrm{MW}$, with solar share of $20 \mathrm{MW}$ based on parabolic-trough technology integrated with a combined-cycle power plant using natural gas. The power plant is financed from the Global Environmental Facility (GEF) and the Japan Bank for International Development. A $10 \mathrm{MW}$ power plant has been operating in Siwa since March 2015, and the remaining plants are expected to be implemented and operated consequentially. The 37 square kilometer Benban Solar Park in Egypt's Western Desert added 800 MW in total installed capacity through 2018, with financing provided by the European Bank for Reconstruction and Development (EBRD), the International Finance Corporation (IFC), and other international financial institutions the 32 individual $20-50$ MW plots will supply $1.5 \mathrm{GW}$ to the grid when the park achieves full capacity by the end of 2019.

\section{Leading Sub-Sectors}

- Wind turbines

- Wind towers 
- Photovoltaic panels and related technologies

- Concentrated solar power equipment and technologies

\section{Opportunities}

In 2012, GOE approved the Egyptian Solar Plan, which includes adding $3.5 \mathrm{GW}$ (2.8 GW CSP and 700 MW PV) of solar energy by 2027. The Ministry of Electricity and Renewable Energy signed seven memoranda of understanding worth USD 500 million for solar and wind projects in Egypt. GOE announced an interim target for the first regulatory period (20152017) to contract 4,300 MW of both solar and wind energy, and a feed-in tariff (FIT) which will allow Egypt to procure $4.3 \mathrm{GW}$ of solar and wind power production by 2017. Its breakdown is as follows: $300 \mathrm{MW}$ for small solar systems, 2,000 MW of medium- and largesize solar plants, 2,000 MW of medium- and large-size wind plants.

According to the Wind and Solar Atlas, there are opportunities and potential for Wind and Solar plants in the East and West Nile areas that will produce around 31,150 MW from wind and 52,300 MW from solar. Egypt is also considering financing options to conduct feasibility studies for the following projects:

- Solar-thermal power plant using CSP technology for both electricity generation and water desalination. Solar-thermal power plant for industrial purposes.

- Designing a technical-financial mechanism to promote the use of solar water heaters in Egypt's residential sector. Local manufacturing of renewable energy equipment.

\section{$\underline{\text { Conclusion }}$}

Currently, transformation toward renewable energy is only a small section of the much larger framework of sustainable development.

The design of cities affects the potential for utilizing renewal energy sources. Different neighborhood forms produce different renewable energy potentials. Comprehensive design approaches could be adopted to increase the renewable energy potential of the development.

Because of the very impacts of fossil fuel, we live in a rapidly urbanizing world, and cities and city regions are central and fertile settings for effective energy policy, programs, and projects. Cities are not only powerful markets for the introduction of renewable energy technologies but also the national and regional seats of political power, and the core settings of cultural discourse and technological innovation. They form the very frameworks for development: local government, planning structures and the powerful civic organizations that are so important in many cultural contexts.

Cities face extraordinary opportunities in the gradual but inexorable transformation toward renewable energy systems from the risky and costly systems of fossil power reticulation to a world of sustainable, affordable, diverse, and ultimately ubiquitous energy management. The hope is one of growing choice in scales of operation and levels of technological sophistication. Fundamental changes in urban power regimes that are in keeping with sustainable development practices promise to revitalize development in urban areas and boost urban business and technological innovation. And by pursuing energy reform strategies in 
keeping with globally sustainable greenhouse gas emission levels, local urban leaders can also act globally by helping achieve greater equity and justice in international development. Thus, in the authors point of view one of the most important barriers that needs a quick solution is the user or local awareness problems. Our society needs to know more about global warming and need to understand what RE and through media RUE is, governmental awareness programs, educational sectors and others. To promote and aware students within all education levels about the use of RET to decrease carbon dioxide emissions all over the world and save our planet from global warming disasters as today's kids are tomorrows men.

To support the further expansion of renewable energy resources, it will also be necessary to rebuild regional structures in a way that matches available resources to the existing demand for energy services as closely as possible. It will therefore be important to provide regional resource management plans and to develop and implement local and regional energy strategies. Moreover, it has been argued that a reallocation of political and legal competences would be essential - one that goes across and beyond the existing political-administrative structures.

Finally, that such transformation will be possible; the necessary renewable energy sources are present, if further technological improvements of the energy system are achieved, especially technologies of converting the transportation and the introduction of flexible energy system technologies are crucial. Therefore, the renewable environmentally friendly energy must be encouraged, promoted, implemented, and demonstrated by full-scale plan. 


\section{References}

1. Roorda, C. \& Wittmayer, J., 2014, Transition governance in five European cities - an evaluation, Dutch research institute for transitions (DRIFT), Erasmus University Rotterdam.

2. Nirmala Rao, Reader in Politics and Head of Department of Social Policy and Politics Nirmala Rao ,2008, city in transition: growth, change and governance in six metropolitan areas, Routledge

3. Rotmans J., Kemp R. and van Asselt M., 2001, more evolution than revolution: Transition governance in public policy. Journal of Future Studies, Strategic Thinking and Policy

4. Rotmans, Jan and Loorbach, Derk ,2009, complexity and Transition governance 13 (2), pp. 184-196

5. Kemp René, Loorbach, Derk \&. Rotmans, Jan, 2007, Transition governance as a model for managing processes of co-evolution towards sustainable development, In: International Journal of Sustainable Development \& World Ecology, vol. 14, pp. 7891.

6. Elzen, Boelie; Geels, Frank W.; Green, Ken, 2004, System innovation and the transition to sustainability Theory, evidence and policy, Cheltenham, UK, Northampton.

7. Roorda, C., Wittmayer, J., Henneman, P, Steenbergen, F. van, Frantzeskaki, N., Loorbach, D., 2014, Transition governance in the urban context: guidance manual, Dutch research institute for transitions (DRIFT), Erasmus University, Rotterdam, Netherlands.

8. Frantzeskaki, N., Hölscher, K., Bach, M., Avelino, F.,2018, Co--creating Sustainable Urban Futures, A Primer on Applying Transition Management in Cities, Springer

9. Derk Loorbach, Julia M. Wittmayer, Hideaki Shiroyama, Junichi Fujino, Satoru Mizuguchi,2016, Governance of Urban Sustainability Transitions, Springer

10. Dutch research institute for transitions, DRIFT, 2011, Urban Transition governance Manual, Version 2 - April 13th 2011.

11. Viktor Scherer, Detlef Stolten, 2013, Transition to Renewable Energy Systems, John Wiley \& Sons

12. Hans-Joachim , Hans-Joachim and other,2009, World in Transition, Towards Sustainable Energy Systems, Earthscan

13. Tanay S1dk1 Uyar, 2020, Accelerating the Transition to a $100 \%$ Renewable Energy Era, Springer Nature.

14. Frank Reinier Bruinsma, Jeroen C. J. M. van den Bergh, 2010, managing the Transition to Renewable Energy, Theory and Practice from Local, Regional and Macro Perspectives, Edward Elgar Publishing.

15. Damian Flynn, Damian Flynn, 2019, Advances in Energy Systems, The Large-scale Renewable Energy Integration Challenge, John Wiley \& Sons.

16. Pao-Yu Oe, Christian Breyer, 2020, Pathways and Implementation, 100\% Renewable Energy Transition, MDPI. 
17. https://www.futurelearn.com/courses/energy-transition/0/steps/10198

18. IRENA,2018, Renewable energy Outlook Egypt

19. https://energypedia.info/wiki/File:Egyptian Electricity Generation from Renewables by S ource $(2015$,IEA).png

20. https://www.irena.org/publications/2018/Oct/Renewable-Energy-Outlook-Egypt

21.A. Khalil *, A. Mubarak, S. Kaseb, 2010, Road map for renewable energy research and development in Egypt, Journal of Advanced Research (2010) 1, 29-38

22. https://english.aawsat.com/

23. Julia Wittmayer, Chris Roorda, Frank van Steenbergen,2014, Governing Urban Sustainability Transitions - Inspiring examples, (DRIFT), Erasmus University, Rotterdam, Netherlands.

24. Dutch research institute for transitions, DRIFT, 2011, Urban Transition governance Manual, Version 2 - April 13th 2011.

25. YAN YANG, 2010, sustainable urban transformation: driving forces, indicators and processes, PHD dissertation, ETH ZURICH.

26. Marta Olazabal and Unai Pascual,2014, Identifying social determinants of urban low carbon transitions: the case of energy transition in Bilbao, Basque Country

27. Chris Roorda, Julia Wittmayer, 2014, Transition governance in five European cities an evaluation, (DRIFT), Erasmus University, Rotterdam, Netherlands.

28. Aberdeen City Council ,2013, Aberdeen in Transition - journey towards 2050

29. Website MUSIC-project in Aberdeen: www.aberdeencity.gov.uk/musicproject

30. Kemp René, Loorbach, Derk \&. Rotmans, Jan, 2013, Transition governance as a model for managing processes of co-evolution towards sustainable development. In: International Journal of Sustainable Development \& World Ecology

31. Website drift-www.drift.eur.nl

32. Loorbach, D., 2010, Transition governance for Sustainable Development:a Prescriptive, Complexity-Based Governance Framework. Governance 